Theory: State of the Art Review [Invited Paper]

\title{
Self and Identity in Personality Psychology
}

\author{
Dan P. McAdams ${ }^{1}$ (D), Kali Trzesniewski² (D) , Jennifer Lilgendahl ${ }^{3}$ (D) , \\ Veronica Benet-Martinez ${ }^{4}$ (D) , Richard W. Robins ${ }^{2}$ (D)
}

[1] Department of Psychology and Program in Human Development and Social Policy, Northwestern University, Evanston, IL, USA. [2] Department of Psychology, University of California, Davis, CA, USA. [3] Department of Psychology, Haverford College, Haverford, PA, USA. [4] Department of Social and Political Sciences, Pompeu Fabra University, Barcelona, Spain.

Personality Science, 2021, Vol. 2, Article e6035, https://doi.org/10.5964/ps.6035

Received: 2021-01-31 • Accepted: 2021-04-20 • Published (VoR): 2021-06-21

Handling Editor: John F. Rauthmann, Bielefeld University, Bielefeld, Germany

Reviewing: Round 1 - Alain Morin; Anonymous \#1; Anonymous \#2. No open reviews are available

Corresponding Author: Dan P. McAdams, Department of Psychology, Northwestern University, 2120 Campus Drive, Evanston, IL 60208, USA. E-mail: dmca@northwestern.edu

\begin{abstract}
Research on self and identity has greatly enhanced personality science by directing inquiry more deeply into the person's conscious mind and more expansively outward into the social environments that contextualize individual differences in behavior, thought, and feeling. After delineating key concepts and offering reasons why personality psychologists should care about self and identity processes, we highlight important empirical discoveries that are of special relevance to personality science in the areas of (1) self-insight, (2) self-conscious emotions, (3) self-esteem, (4) narrative identity, and (5) the role of culture in shaping self, identity, and the integration of personality. We anticipate that future research will also move vigorously to (1) develop more comprehensive and precise accounts of how life experiences influence the development of self and identity, (2) explore more fully how the brain builds a sense of self, and (3) harness what we know about self and identity to improve people's lives and promote personality development.
\end{abstract}

\section{Keywords}

self, identity, personality, self-conscious emotions, self-esteem, narrative identity, culture, self-awareness 


\section{Relevance Statement}

The paper teases apart different meanings for the terms "self," "identity, and "personality" and provides a state-of-the-art appraisal of the role of self and identity in the study of human personality.

\section{Key Insights}

- Personality is a thing; self is a perspective.

- Self-processes integrate and contextualize personality.

- Self-esteem follows a normative developmental trajectory.

- Narrative identity captures the stories people live by.

The study of self and identity moves personality psychology in two directions: deeper inside the conscious mind of the person and further out into the person's social world.

Moving inside the mind, consider the subjective experience of a highly narcissistic person, like Donald J. Trump (McAdams, 2020). As the 45th president of the United States, Trump's socially dominant and ferociously antagonistic interpersonal style tracked expectations for an actor high in extraversion and very low on agreeableness. But many of the specific actions he took as president - from courting white supremacists in 2017 to withholding military aid for Ukraine in 2018 (for which he was impeached) to actively denying the threat of the Coronavirus in 2020 - make no psychological sense without considering the peculiar way in which Mr. Trump reflexively understood himself. In each of these instances, Trump aimed to bolster his narcissistic self-image by operating as what McAdams (2020) called the episodic man. As such, Trump fought furiously to win each immediate episode in life, moment by self-glorifying moment, scene by discrete scene. But he formed no long-term personal narrative in his consciousness to tie these episodes together, and no resultant long-term plan capable of achieving policy ends. A key to understanding Trump's personality, therefore, is apprehending his fractured selfhood, in constant need of a renewed or refreshed glorification, from one disconnected episode in life to the next.

Moving outside to the social world, consider the social identities of many immigrants from North Africa and Turkey who live today in Europe, or of Mexican Americans in the United States. Beyond and beneath the dispositional personality traits that influence their daily behavior lie characteristic beliefs, values, goals, and stories that are inflected by different (and sometimes conflicting) identities. Many of these people feel as if they are living in two worlds, expressing a bicultural identity (Benet-Martínez \& Haritatos, 2005). Ethnicities, religious traditions, gender norms, social class mores, power structures in society, and a range of other outside sources for identity shape what people do, what they feel, and how they think - increasingly so as modern societies become more diverse and people increasingly find themselves in culturally complex situations 
(Benet-Martinez, 2018). Social identities promote connections to and a sense of belonging within groups. Considerations of self and identity broaden personality psychology's engagement of person-by-situation interactions. By shifting attention to the outside social and cultural world, scientific inquiry into self and identity helps to more fully contextualize the study of the person.

Going as far back as William James (1892/1953), George Herbert Mead (1934), and Erik Erikson (1950), the classic psychological writings on self and identity emphasized both inner phenomenal experience and the outer world. Selfhood is fundamentally about how a subject (the "I") relates to itself as an object (the "me"). As such, selfhood is revealed through an ongoing sense of self-awareness ("I") and through the more-or-less stable self-representations ("me") that people discover, construct, and work on (Robins, 2021). The former moves us inside the mind, to explore inner subjectivity, while the latter moves us outward to the various autobiographical events, cultural categories, and social realities that people come to see as part and parcel of who they are. Both moves - inward and outward - are necessary for developing a full, and fully contextualized, understanding of personality. Both moves, moreover, ultimately arrive at the same psychological destination, for a person's social world penetrates the mind and becomes reflected within it. By helping to push personality psychology further in and further out, the exploration of self and identity enriches our understanding of the personality processes involved in generating and regulating behavior, thought, and feeling.

\section{What Is the Relationship Between "Personality" and "Self"?}

In everyday talk, the terms "personality" and "self" are often used interchangeably. Both terms refer to the kind of person a person is. When considering those especially broad and enduring psychological features that distinguish one person from the next, we often speak of personality "traits," such as the broad dispositions of conscientiousness and agreeableness. Psychologists often measure individual differences in traits through self-report scales. Doesn't that mean, therefore, that traits are as much a part of "self" as they are a part of "personality"? If yes, then what is the difference between personality and self?

For the purposes of this paper, we see the main difference to be this: Personality is a thing; self is a perspective. Going back to Allport (1937), psychologists have conceived of personality as an organized set or system of internal psychological features, mechanisms, and dynamic processes that spell out, influence, and/or mediate the person's characteristic manner of interacting with (and adapting to) the world. Whereas some conceptions of personality prioritize dispositional traits over all other constructs (McCrae \& Costa, 2008), others broaden the net to include social-cognitive variables, values, goals, motives, life stories, and other personalized processes and mechanisms (McAdams \& Pals, 2006; 
Mischel \& Shoda, 1995). Regardless of their scope, however, different approaches to personality generally assume that personality itself exists within the individual in an objective, third-person sense. That is, people have (possess, own) their personality traits and motives, values, dynamic processes, and so on. Many of these features of personality may be observed, accessed, measured, and monitored through a host of different methods that go well beyond self-report, including those that tap into implicit or unconscious features and processes of personality. Importantly, a person does not need to know that they have a personality in order to have one. Self-awareness is not necessary. Even human infants have personalities, expressed mainly as temperament traits - as do many species of nonhuman animals (Weiss, 2021).

By contrast, the self is not a thing, but instead it is the reflexive perspective from which a thing encounters itself (Harre, 1997; Leary, 2004). Whereas personality is knowable from a third-person perspective, the self is the first-person relationship between "I" (the subject) and "Me" (the object). As William James (1892/1953) famously suggested, a person (as I) may reflexively attribute an infinitude of qualities to the self (as Me), including personality traits, of course, but also characteristics of body and physiology, important interpersonal relationships and social roles, and even aspects of the material world. For example, a woman may consider herself to be an extravert, a Social Democrat, a Serbian, a lesbian, a good mother, a negligent daughter, an environmentalist, the owner of a beautiful automobile, a wine connoisseur, middle-aged, Laura's best friend, somebody who dislikes football, and marvelously thin for her age. These are all features of (her) self, as attributed by the I to Me. Only one of them, however, refers explicitly to a personality trait (extraversion). In one sense, then, the self is more expansive than personality. But in another (more psychological) sense, the self is more restricted in that any features of personality that are not potentially the object of the subject's awareness (such as implicit processes and unconscious dynamics) are ipso facto not self.

The personality trait of extraversion exists independently of the self (even if it is often measured through self-report) in that extraversion can be readily observed and assessed from other (non-self) vantage points (through peer ratings, for example, naturalistic observations, and so on). Beyond dispositional traits, however, certain other psychological constructs - that either bear directly on personality or may be considered self-reflexive features of personality itself - bring the I/Me dynamic explicitly into play, such as self-esteem, narcissism, self-complexity, and self-compassion. Unlike personality traits, these constructs owe their very existence to the self's reflection on itself. Similarly, many psychological conceptions of identity (e.g., Baumeister, 1986; Erikson, 1950; Marcia et al., 1993) describe reflexive products of the I/Me dynamic. For example, narrative identity refers to the integrative story that "I" tell about "Me" (McAdams \& McLean, 2013). Conceptions of self and identity play major roles in differentiating one person from the next and in shaping overall adaptation to life. 
Finally, researchers often contrast the (1) broad traits of personality, such as those encompassed within the Big Five framework, with the (2) more specific selves, identities, and social roles that people assume and construct in their daily lives. Whereas personality psychologists tend to emphasize the former, social psychologists may focus more on the latter. Accordingly, personality psychologists assert that traits account for broad consistencies in behavior, thought, and feeling across different selves, identities, and roles, whereas social psychologists tend to emphasize the specificity of expression within particular self domains, noting differences more than cross-context commonalities. We see these two general approaches as complementing each other. Decades after the situationist critique in personality science, we believe that it is now incontestable that broad traits account for cross-situational consistencies and predict consequential life outcomes (Fleeson \& Gallagher, 2009; Ozer \& Benet-Martinez, 2006). Traits often reveal broad socio-emotional continuities in the ways that human beings, as social actors, perform their roles and assume their identities. At the same time, approaches that emphasize self and identity, including those that are influential within social psychology, frequently show how people often behave, think, and feel in strikingly specific ways under the guise of a particular self perspective, even to the point sometimes of defying their dispositional trait tendencies.

\section{Why Should Personality Psychologists Care About Self and Identity?}

\section{The Self Makes Us Human}

An expansive and diversified sense of selfhood is a cardinal psychological feature of Homo sapiens. While a few other species show self-recognition behavior and certain great apes can be trained to express primitive linguistic markers for "me," no other animal comes close to experiencing and utilizing the rich panoply of I/Me constructions that characterize human selfhood. The capacity for self-awareness and self-representations seems to be a universal characteristic of humans (Robins, 2021). In all human cultures, people have an awareness of their own thoughts and feelings and have relatively stable representations of themselves. The universality of these basic aspects of the self is a striking and highly significant fact that is often overlooked in light of the substantial individual and cross-cultural variability that exists in the way the self is manifested. Over the past few decades, research has documented many ways in which self and identity influence how people think, feel, and act in particular situations, the goals they pursue in life, and the ways they cope with and adapt to new environments. For example, adopting an especially compassionate perspective on one's self (high self-compassion) is associated with greater resilience and positive coping in response to major life stresses, such as divorce, eating disorders, and chronic health issues (Bluth \& Neff, 2018). As another 
example, research has shown that dividing one's self-concept into many different parts (high self-concept differentiation) usually denotes a lack of integration in selfhood, and is consistently associated with lower psychological adjustment (Bleidorn \& Ködding, 2013).

\section{Self and Identity Are Key Mechanisms Underlying Personality Stability and Change}

Human beings possess a motivation to self-verify - that is, to seek out and accept input from others that confirms their already formed view of self (Kwang \& Swann, 2010). As such, self-verification processes promote personality stability over time. That said, people sometimes take stock of themselves and decide they need to change. Their selfdetermined plans and activities may indeed result in change in personality traits, albeit usually modest change (Hennecke et al., 2014; Wrzus \& Roberts, 2017). Normative meanlevel changes in traits over the adult life course (such as increases in conscientiousness and agreeableness and declines in neuroticism) are often tied to identity commitments around work and family roles. At the same time, those identity commitments may help to create stable environments going forward that, in turn, promote temporal stability in traits. The stories people create regarding continuity and change in their lives, moreover, appear to influence their personality development. Research has shown, for example, that adults who process negative life events in especially deep and probing ways tend to show increases in personality maturity in subsequent years (Lilgendahl et al., 2013).

\section{Problems in Self and Identity Figure Prominently in Personality Disorders and Psychopathology}

Whereas certain diagnoses of psychopathology may be profitably construed in terms of extreme scores on specified personality traits, it is also clear that many mental disorders are, at their psychological heart, disorders of human selfhood (Shahar, 2020). In many cases of schizophrenia, for example, the reflexive relationship between "I" (self-as-subject) and "me" (self-as-object) may dissolve (Lysaker \& Lysaker, 2010). The person may no longer feel ownership of the self - thoughts, feelings, and experiences may no longer feel as if they are "mine." In borderline personality disorder, a person may be unable to construe life as an ongoing narrative, continuous in time (Shiner et al., 2021). Indeed, the breakdown of temporal continuity in subjective experience has been identified as a cardinal feature of many psychological maladies, including numerous personality disorders, anxiety disorders, and PTSD (Shahar, 2020). Low self-esteem is central to depression, and excessive self-criticism, along with pathological objectification of the body, often accompanies eating disorders. Wildly fluctuating self-esteem characterizes bipolar disorder and may play a role in narcissistic personality disorder as well. 


\section{What Are the Important Discoveries About the Role of Self and Identity in Personality?}

Over the past few decades, researchers have accumulated countless empirical findings on the nature of self and identity, many of which qualify as conceptually seminal and robustly replicated results. Below, we summarize what we consider to be among the most noteworthy findings from five areas of research: (1) self-insight, (2) self-conscious emotions, (3) self-esteem, (4) narrative identity, and (5) culture and the self.

\section{People Have Moderately Good Self-Insight}

The study of self-insight has been an abiding issue dating back at least to Socrates' proclamation to "Know Thyself." But to contemporary personality psychologists, self-insight is not just a philosophical issue. Much of what we know about personality is based on self-report measures that depend critically on the degree to which people can (and do) report accurately on their behavioral, cognitive, and affective tendencies.

Supporting the validity of self-report personality assessment, research suggests that people have moderately good insight into their talents, abilities, and traits. Studies consistently demonstrate that people's ratings of these characteristics show reasonably strong associations with how they are perceived by others, as well as with objective indicators of the traits themselves (Schriber \& Robins, 2012). Even young children (Harris et al., 2018) and individuals with autism (Schriber et al., 2014) show significant levels of self-other agreement in their ratings of personal characteristics. Pitting self-reports against reports from others, there is some evidence that certain traits (e.g., neuroticism) are somewhat more accurately tapped through self-report whereas others (e.g., extraversion) may be more accurately assessed through ratings made by others (Vazire, 2010).

Despite the fact that people show moderately good self-insight, motivational, cognitive-informational, and neurological factors can limit the accuracy of self-perceptions. Motives for self-enhancement may shift self-ratings in a more positive direction; motives for self-verification may promote consistency in self-ratings; and motives for self-improvement may urge the person to see the present self as superior to the past self. On average, people tend to show a small (about $1 / 3$ of a standard deviation) positivity bias in their self-ratings, but individuals vary substantially in the degree to which they are susceptible to this effect, with some individuals systematically inflating their self-views and others self-diminishing (Schriber \& Robins, 2012). Narcissistic individuals, like Donald Trump, hold particularly biased self-perceptions, perhaps because acknowledging the truth about themselves would lead to painful feelings of shame and burst the bubble of their inflated pride (Krizan \& Herlache, 2018).

Self-insight can also serve as a powerful tool for self-improvement. Recent work suggests that self-nudging can be an effective way to help people create and maintain behavior changes (Reijula \& Hertwig, 2020). Increasing a person's insight into their 
behavioral patterns (including recognizing when these patterns are not in line with ideals and goals) can lead to sustained changes and better life outcomes.

\section{The Self Is the Basis for an Entire Class of Emotions}

Emotions provide the fuel for a wide range of personality processes. Among the most consequential are the self-conscious emotions of pride, shame, guilt, and embarrassment (Tracy et al., 2007). Emerging in the second and third years of life (see Figure 1), self-conscious emotions, require the ability to evaluate oneself from the perspective of actual or imagined others. Self-conscious emotions guide behavior by compelling people to do things that are socially valued and avoid doing things that elicit social condemnation. An individual may strive to be a "good daughter," or a "devout Muslim," because doing so makes them feel proud of themselves - and failing to do so may make them feel guilty or ashamed of themselves. By reinforcing adaptive social behaviors-encouraging people to act in ways that promote social status (getting ahead) and acceptance (getting along) -self-conscious emotions help people adapt to social challenges. And self-conscious emotions may also manifest themselves when adaptation fails.

Guilt, for example, is centrally involved in reparative and pro-social behaviors such as empathy, altruism, and caregiving (Tracy et al., 2007). Shame, by contrast, mediates the negative physical and emotional consequences of social stigma. High levels of shame are associated with depression, chronic anger, and the narcissistic, antisocial, and borderline personality disorders. Pride motivates moral and prosocial behaviors and has been linked to greater perseverance, approach motivation, and performance in achievement contexts. However, the general findings on pride gloss over a more complex reality. Specifically, meta-analytic studies suggest that authentic pride (achievement-based) is linked to high levels of conscientiousness and low levels of anxiety and depression, whereas hubristic pride (self-glorifying) is linked to low agreeableness and poor mental health (Dickens \& Robins, 2020). Both authentic pride and hubristic pride are associated with narcissistic personality processes, which themselves are often driven by alternating feeling states of pride and shame.

Self-conscious emotions shed light on certain trait-behavior relationships. For example, conscientious individuals are more guilt prone (Fayard et al., 2012), which might help elucidate the process by which conscientiousness leads to healthier lifestyles and better overall health. Since guilt motivates reparative behaviors, conscientious individuals may be more likely to exercise after feeling guilty about overeating or indulging in fatty foods. 


\section{Figure 1}

Milestones in the Development of Self and Identity

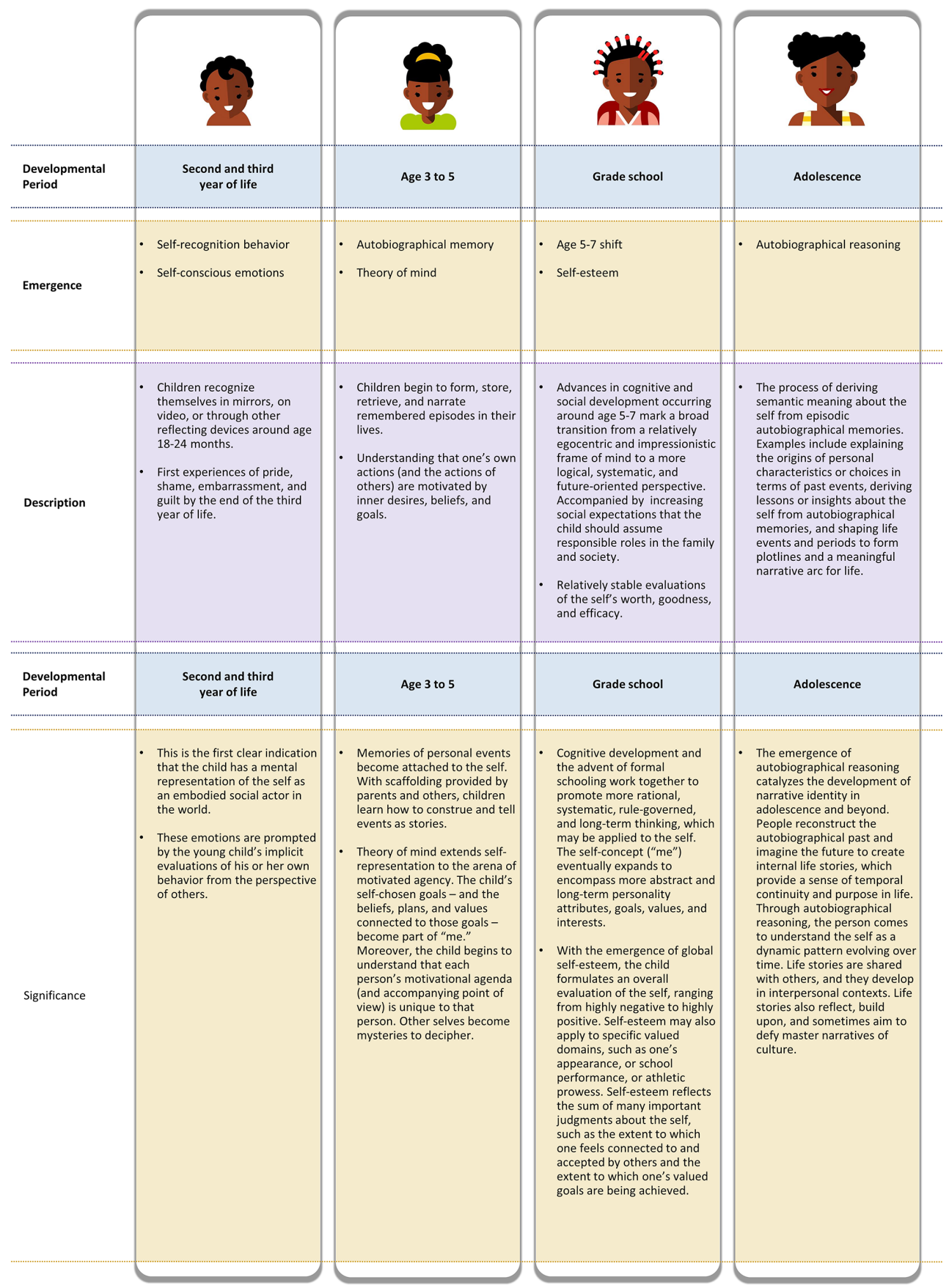

Personality Science

2021, Vol. 2, Article e6035

https://doi.org/10.5964/ps.6035 


\section{Self-Esteem Is a Trait-Like Construct With Important Real-World Consequences}

Although features of human selfhood are phenomenological in nature, they are no less real than personality traits. Take self-esteem as an example, which exhibits the same kind of properties that personality psychologists attribute to dispositional traits (like those encompassed within the Big Five). These properties include stability over time, cross-situational consistency, a genetic basis, normative developmental pattern, and real-world consequences.

Self-esteem is stable over time. The rank-order stability of self-esteem is quite high even across decades of life, and comparable in magnitude to the rank-order stability of personality traits (Trzesniewski et al., 2003). As with personality traits, moreover, the rank-order stability of self-esteem varies as a function of age; it is relatively low in childhood, increases across adolescence, peaks in adulthood, and then decreases in old age (Trzesniewski et al., 2003). The longitudinal continuity in self-esteem is partly due to its genetic base. Behavioral genetic research suggests that both genetic and environmental factors influence self-esteem, with the heritability of self-esteem estimated to be about $40 \%$ (Orth \& Robins, 2019).

Self-esteem also shows cross-situational consistency. People's evaluations of their worth and competence in one domain (e.g., academics) tend to correlate moderately highly with their self-evaluations in other domains (peer relationships, physical appearance, etc.). All domain-specific evaluations correlate with global self-esteem.

As indicated in Figure 2, self-esteem development follows a normative trajectory. Around the age of 5, children first begin to form stable evaluations of their overall worth as a person, providing reliable and valid reports of their global self-esteem (e.g., Harris et al., 2018). As they grow up, mean levels of self-esteem tend to increase slightly from the preschool years to middle childhood, plateau in early and middle adolescence, increase sharply from around age 15 into young adulthood, continue to increase across adulthood, and then decline in old age, with a sharp drop among those over 90 years of age. This normative trajectory appears to hold across gender, nationality, ethnicity, and birth cohort (Orth et al., 2018).

Individual differences in self-esteem exert well-documented real-world consequences. People with high self-esteem tend to have more satisfying social and romantic relationships, more success in school and work, better health, and lower levels of depression and criminal behavior, compared to persons with low self-esteem (Orth et al., 2012; Robins, 2021).

\section{Narrative Identity Captures the Stories People Live By}

A growing body of research in personality and developmental psychology demonstrates that people form and maintain a sense of identity over time through the construction of 
Figure 2

Mean-Level Change of Self-Esteem From Age 4 to 94 Years

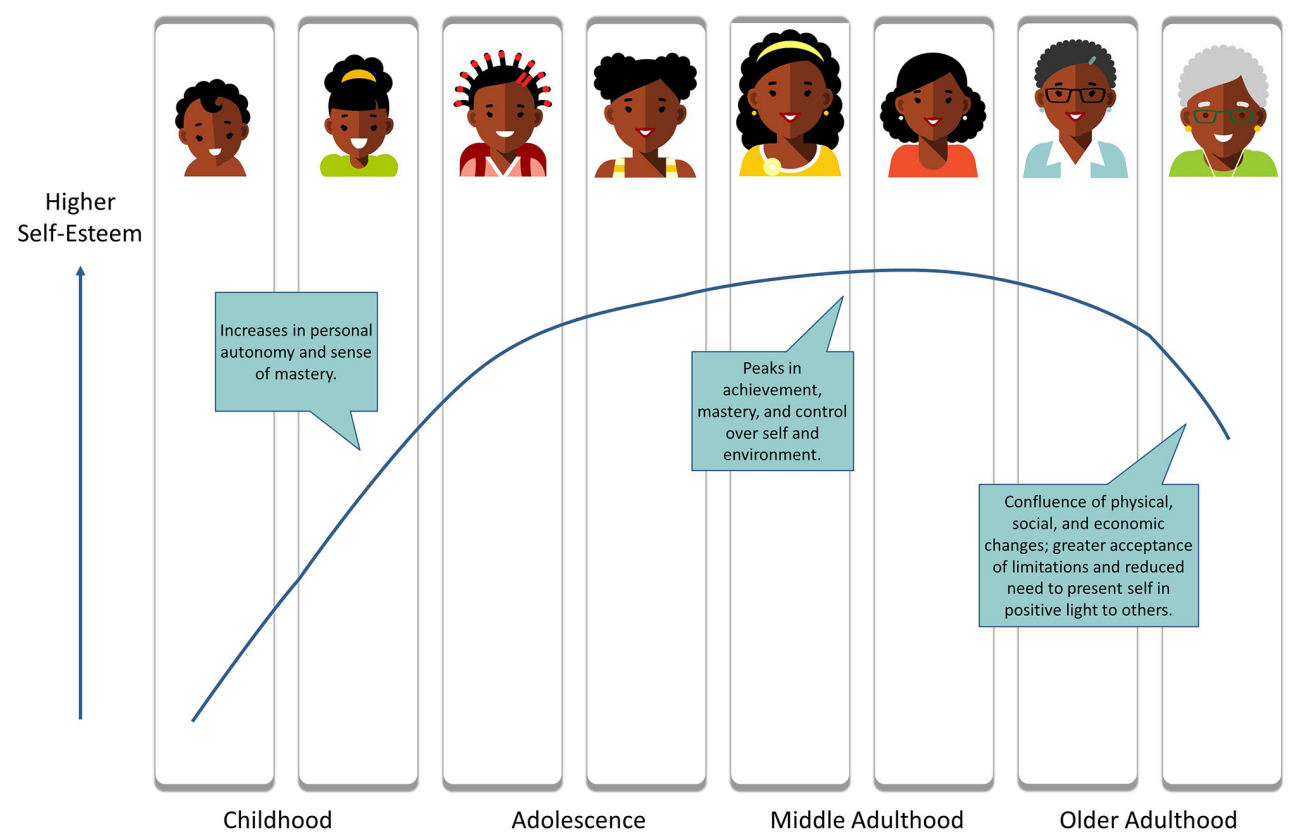

Note. Adapted from Orth, Erol, \& Luciano's (2018) meta-analysis of longitudinal studies.

life stories (McAdams, 2021). Narrative identity is a person's storied understanding of self as situated across the reconstructed past and the imagined future (McAdams \& McLean, 2013). The internal story provides a person's life with a sense of temporal continuity and an understanding of "how I have become the person I am becoming." Relying mainly on interviews and open-ended methods, research on narrative identity typically asks participants to recount and interpret important autobiographical events, which are later coded for various themes and structures.

While the origins of narrative identity may be traced back to childhood conversations and storytelling, narrative identity in its full form does not arrive until adolescence, when the capacity for autobiographical reasoning emerges (Habermas \& Bluck, 2000) as indicated in Figure 1. Autobiographical reasoning refers to the process of deriving meanings about the self from episodic events in life. From adolescence through midlife, autobiographical reasoning grows in scope and sophistication, with an increasing focus on wisdom, insight, positivity, and growth from negative events (McAdams, 2021).

Individual differences in the stories people tell about their lives may be grouped into at least three main categories: (1) motivational and affective themes (e.g., agency, 
communion, positive emotion); (2) meaning making (e.g., deriving lessons or insights from events, elaborative processing of events); and (3) structural qualities (e.g., the complexity of narrative accounts, their relative coherence) (McLean et al., 2020). Research has consistently shown that people whose narrative identities feature the motivational themes of self-efficacy (agency) and closeness to others (communion), and interpret the meaning of negative personal events through the lens of redemption, tend to enjoy higher levels of psychological well-being, compared to those whose narrative identities do not showcase these patterns. Furthermore, these adaptive aspects of narrative identity have incremental validity in predicting well-being over and above the Big Five traits (Adler et al., 2016).

Narrative identity is closely linked to the adult-developmental concepts of generativity and ego development. Highly generative adults show a distinct pattern of life story narration that is characterized by the redemptive transformation of bad into good, concern for those less fortunate, and living a life guided by strong moral principles (McAdams \& Guo, 2015). In other words, adults who focus outward on others and are motivated to improve the world for the next generation - a psychosocial hallmark of maturity in midlife - tend to construct narrative identities that justify and support those goals. Increases in ego development over time, which reflects one's level of cognitive and emotional complexity and awareness of oneself in relation to the world, have been associated with accommodative processing of difficult live events. That is, narrating life's biggest challenges in ways that incorporate new and more sophisticated understandings of self, others, and the world into one's life story contributes to personality change in the form of ego development (Lilgendahl et al., 2013).

In making narrative sense of their own lives, people draw from the favored stories, plotlines, characters, images, and themes that prevail in their culture. Life narratives may reveal important truths and variations in the lived experiences associated with inhabiting marginalized identities, identities in which individuals deviate from powerful master narratives that pervade culture and shape and constrain processes of identity development (McLean \& Syed, 2015). Research on the cultural shaping of narrative identity reveals important individual differences in how marginalized groups navigate identity development, revealing how this process is inextricably tied to social/cultural factors that often reflect inequities in power, privilege, and social status (Hammack, 2008).

\section{Culture Shapes Identity While Challenging People to Integrate Their Lives}

Research in personality, developmental, social, and cognitive psychology supports the broad proposition that people have multiple interrelated selves that are shaped by their interactions with and their positions in a complex socio-cultural context. People develop their selves through a dynamic, continuous, and reciprocal process of transaction with their social environments. A fundamental organizing force behind these environmental 
influences, affordances, and products is culture. Through the institutions, meanings, and practices that comprise it, culture accounts for a significant portion of the objective and symbolic macro- and micro-conditions which influence whether and how certain aspects of the self develop and are expressed - for example, the value given to ego-focused traits such as self-esteem (Tsai, 2007), or whether self-disclosure and self-expression are normative.

But people are not passive recipients of cultural forces. Individuals internalize culture's different elements selectively, often by building particular versions of, for example, an American, Spanish, or Japanese "way of life." This variation results in a great deal of within-culture heterogeneity. Further, individuals may deviate, willingly or unwillingly, from the dominant cultural norms and expectations (e.g., ethnic or sexual minorities) and construct alternative self-definitions and social niches that themselves become new "cultures" (McLean \& Syed, 2015).

Culture, nationality, and ethnicity often relate to events and qualities (e.g., birthplace, citizenship, skin color, historically shared narratives, personal memories, shared norms and values) that are seen as essential to a person's identity (Oishi et al., 2021). Moreover, selves are also guided by the meanings, norms, and values attached to particular genders, religions, generational cohorts, and social classes. Other forms of social belonging such as sexual orientation, political affiliation, and profession also provide opportunities for the creation of culturally contoured identities. Think, for instance, of the military profession and its emphasis on strict norms (culture of tightness), the premium the male gender places on agency and autonomy (cultural individualism), or Muslims' concerns with virtue and social reputation (culture of honor).

Whereas in some cases multiple cultural forces may create a fragmented self for a given person, in others multiplicity may confer complexity and richness. People may also effectively switch between their different social selves in response to relevant situational cues. With respect to personality processes, an important individual difference for many people is the ability to integrate different culturally inflected selves within a harmonious and synergistic whole. Shaped by personality and other factors, the ability to integrate different cultures within one's identity promotes psychological adjustment, creativity, work and family engagement, and positive intergroup attitudes. It may be a psychologically indispensable skill for navigating through a culturally diverse and complex modern world (Benet-Martinez, 2018).

\section{What Directions Should Research on Self and Identity Follow in the Future?}

The literature on self and identity is enormous, and so too are the possibilities for future research. Below we highlight several future directions that we believe are important to pursue. 
First, we need a more complete developmental account of how life experiences shape features of self and identity. For example, although we know that environmental factors account for more of the variance in self-esteem than genetic factors, parenting and other aspects of the family environment generally have weak and inconsistent effects (Krauss et al., 2020). Similarly, although we have a good understanding of how the capacity to narrate one's life develops (see Figure 1), we need to learn more about the factors and experiences that determine why, for example, one person develops a complex and cohesive narrative identity centered around themes of agency and redemption while another person develops a comparatively simple identity centered around communal themes.

Second, we have only a rudimentary understanding of how the brain builds a sense of self. It is generally assumed that self and identity are generated by specific types of information processing computations, physically realized by the hardware of the brain, but the details of this process, or which hardware is involved, are still unknown. Neuroimaging studies and studies of patients with neurological damage have identified specific brain regions and neural circuitry associated with different self and identity processes (Beer, 2016; Robins, 2021). For example, functional magnetic resonance imaging (fMRI) studies converge with patient studies in showing that several regions within the frontal and temporal lobes, including the medial prefrontal cortex, dorsolateral prefrontal cortex, medial frontopolar-retrosplenial cortex, orbitofrontal cortex, and anterior cingulate, are more heavily recruited when individuals engage in self-related processes or experience self-conscious emotions (Beer, 2016; Tacikowski et al., 2017).

One interesting question emerging from this research is what happens in the brain when participants are not performing any mental tasks but are simply engaging in self-reflection. It turns out that a set of brain regions in the frontal, parietal, and medial temporal lobes consistently become active when people let their minds wander and engage in self-reflection, mentally traveling back and forth through time to learn from the past and plan for the future (Axelrod et al., 2017). Neuroscientists refer to this activity as the brain's "default mode network," suggesting that we spend much of our time exploring past and future selves. The default mode network has also been shown to be highly activated when people are engaged in thoughts of social interaction and social relationships.

While new research seems to promise new insights to come, it must be conceded that many of the brain regions identified in self-processing are not physically and functionally distinct from those used for more general-purpose cognitive processing (e.g., perceiving others), which raises the question of whether there are any brain networks distinct to self and identity (e.g., Gillihan \& Farah, 2005). Moreover, fMRI research is essentially correlational, raising questions about the direction of causality; perhaps the process of self-reflection is generated by alternative neural mechanisms and then regions 
in the frontal and temporal lobes are subsequently recruited to act on the products of self-reflection.

Third, how can we harness what we know about self and identity to improve lives and promote personality development? Theories of personality development suggest that the self and identity - as captured in motivational processes, self-regulatory efforts, and self-reflection - are core mechanisms for changing personality. For example, the TESSERA framework (Wrzus \& Roberts, 2017) proposes that motivation (e.g., intentions, goals) and reflective processes (e.g., self-reflection, self-narration) are the primary mechanisms for inducing personality change. Similarly, Dweck (2017) posits that goal pursuit, self-related beliefs, and self-representations are intimately tied up with personality development and change. Both models also focus on repetition, which requires self-regulation of thoughts, feelings, and behaviors to meet desired goals. Hudson et al. (2019) found that people can change their personality when they have the desire to change and actively pursue the goal of change. Similarly, Atherton et al. (2021) found co-development of personality and life goals, concluding that individuals self-regulate by formulating goals that are consistent with their personality traits. Conversely, placing importance on certain goals promotes changes in corresponding traits, presumably because investing in goal-relevant contexts places rewards, punishments, and contingencies on certain traits.

Taken together, this literature suggests that self and identity play key roles as mechanisms of personality change. However, more research is needed to identify ways to apply these ideas to improve lives. Researchers need to identify which methods of change work best, for whom, and under what conditions. Often the approach to addressing questions such as these is to evaluate the role of demographic characteristics (e.g., age, social class, education). However, such broad categories do not always provide insight into mechanisms of change, and are difficult to translate into programs to improve lives. In a promising vein, researchers have recently turned their attention to studying individualized change (Jackson \& Beck, 2021) and the role that individual differences in perception have in promoting, or impeding, change. New approaches propose more dynamic models to study change (Bleidorn et al., 2020), showing promise for developing scalable, individualized interventions that create intentional personality change in diverse populations. The more that we understand how specific self-processes play out for particular people in particular life situations, the more our interventions will help to improve lives.

\section{Conclusion}

Central to the experience of being a human being is the sense that "I am me." From the standpoint of a subject, I can reflect upon myself as an object, evaluate myself, work to regulate and change myself, and develop a socially and culturally shaped identity that explains, for myself and others, how I came to be and where my life may be going. Self 
and identity are intimately tied to personality processes and personality development. Considering processes related to self and identity helps to move personality research deeper inside the conscious mind of the person and further out into the person's social and cultural world.

Over the past few decades, research has documented many ways in which self and identity influence, and are influenced by, how people think, feel, and act in particular situations, the goals they pursue over time, and the ways they adapt to environments. The self is not a mere epiphenomenon. Instead, self-processes decisively shape behavior and influence the quality of life. How we see ourselves, narrate our lives, and conceptualize our social identities matters for important life outcomes. Constructs like self-esteem, self-conscious emotions, self-control, narrative identity, and bicultural identity integration have all been linked to multiple domains of psychological functioning, including achievement, relationships, well-being, and health and longevity, as well as features of psychopathology and mental illness. As research on self-processes continues apace, future studies should shed more light on the neurobiological substrates of human selfhood, the role of life experiences in building self and identity, and the manifold ways whereby self-processes may be marshalled in the service of personality development and improving human lives.

Funding: The authors have no funding to report.

Acknowledgments: The authors have no additional (i.e., non-financial) support to report.

Competing Interests: Dan McAdams is an editorial board member of Personality Science.

Author Contributions: Dan P. McAdams-Idea, conceptualization | Writing | Feedback, revisions | Supervision, mentoring | Project coordination, administration. Kali Trzesniewski-Idea, conceptualization | Visualization (data presentation, figures, etc.) | Writing. Jennifer Lilgendahl-Idea, conceptualization | Writing. Veronica Benet-MartinezIdea, conceptualization | Writing. Richard W. Robins-Idea, conceptualization | Writing.

Ethics Statement: No ethical issues and/or ethics approvals need to be disclosed.

Related Versions: No other previously published versions of this manuscript exist in part or in whole.

\section{References}

Adler, J. M., Lodi-Smith, J., Phillippe, F. L., \& Houle, I. (2016). The incremental validity of narrative identity in predicting well-being: A review of the field and recommendation for the future. Personality and Social Psychology Review, 20(2), 142-175. https://doi.org/10.1177/1088868315585068

Allport, G. W. (1937). Personality: A psychological interpretation. Holt, Rinehart \& Winston. 
Atherton, O. E., Grijalva, E., Roberts, B. W., \& Robins, R. W. (2021). Stability and change in personality traits and major life goals from college to midlife. Personality and Social Psychology Bulletin, 47(5), 841-858. https://doi.org/10.1177/0146167220949362

Axelrod, V., Rees, G., \& Bar, M. (2017). The default network and the combination of cognitive processes that mediate self-generated thought. Nature Human Behaviour, 1, 896-910. https://doi.org/10.1038/s41562-017-0244-9

Baumeister, R. (1986). Identity: Cultural change and the struggle for self. Oxford University Press.

Beer, J. S. (2016). Three questions about the neural basis of self. In E. Harmon-Jones \& M. Inzlicht (Eds.), Social neuroscience: Biological approaches to social psychology (pp. 77-100). Routledge.

Benet-Martinez, V. (2018). Multicultural identity and experiences: Cultural, social, and personality processes. In K. Deaux \& M. Snyder (Eds.), Oxford handbook of personality and social psychology (2nd ed.). Oxford University Press. https://doi.org/https://doi.org/10.1093/oxfordhb/9780190224837.001.0001

Benet-Martínez, V., \& Haritatos, J. (2005). Bicultural identity integration (BII): Components and psychosocial antecedents. fournal of Personality, 73(4), 1015-1050.

https://doi.org/10.1111/j.1467-6494.2005.00337.x

Bleidorn, W., Hopwood, C. J., Back, M. D., Denissen, J. J., Hennecke, M., Jokela, M., Kandler, C., Lucas, R. E., Luhmann, M., Orth, U., Roberts, B. W., Wagner, J., Wrzus, C., \& Zimmermann, J. (2020). Longitudinal experience-wide association studies - A framework for studying personality change. European fournal of Personality, 34(3), 285-300.

https://doi.org/10.1002/per.2247

Bleidorn, W., \& Ködding, C. (2013). The divided self and psychological (mal) adjustment: A metaanalytic review. Fournal of Research in Personality, 47(5), 547-552.

https://doi.org/10.1016/j.jrp.2013.04.009

Bluth, K., \& Neff, K. D. (2018). New frontiers in understanding the benefits of self-compassion. Self and Identity, 17(6), 605-608. https://doi.org/10.1080/15298868.2018.1508494

Dickens, L. R., \& Robins, R. W. (2020). Pride: A meta-analytic project. Emotion. Advance online publication. https://doi.org/10.1037/emo0000905

Dweck, C. S. (2017). From needs to goals and representations: Foundations for a unified theory of motivation, personality, and development. Psychological Review, 124(6), 689-719. https://doi.org/10.1037/rev0000082

Erikson, E. H. (1950). Childhood and society. Norton.

Fayard, J. V., Roberts, B. W., Robins, R. W., \& Watson, D. (2012). Uncovering the affective core of conscientiousness: The role of self-conscious emotions. Journal of Personality, 80(1), 1-32. https://doi.org/10.1111/j.1467-6494.2011.00720.x

Fleeson, W., \& Gallagher, P. (2009). The implications of Big Five standing for the distribution of trait manifestations of behavior: Fifteen experience-sampling studies and a meta-analysis. Journal of Personality and Social Psychology, 97(6), 1097-1114. https://doi.org/10.1037/a0016786

Gillihan, S. J., \& Farah, M. J. (2005). Is self-related processing special? A critical review. Psychological Bulletin, 131(1), 76-97. https://doi.org/10.1037/0033-2909.131.1.76 
Habermas, T., \& Bluck, S. (2000). Getting a life: The emergence of the life story in adolescence. Psychological Bulletin, 126(5), 748-769. https://doi.org/10.1037/0033-2909.126.5.748

Hammack, P. L. (2008). Narrative and the cultural psychology of identity. Personality and Social Psychology Review, 12(3), 222-247. https://doi.org/10.1177/1088868308316892

Harre, R. (1997). The singular self. SAGE.

Harris, M. A., Donnellan, M. B., \& Trzesniewski, K. (2018). The Lifespan Self-Esteem Scale: Initial validation of a new measure of global self-esteem. Fournal of Personality Assessment, 100(1), 84-95. https://doi.org/10.1080/00223891.2016.1278380

Hennecke, M., Bleidorn, W., Denissen, J. J. A., \& Wood, D. (2014). A three-part framework for selfregulated personality development across adulthood. European fournal of Personality Development, 28(3), 289-299. https://doi.org/10.1002/per.1945

Hudson, N. W., Briley, D. A., Chopik, W. J., \& Derringer, J. (2019). You have to follow through: Attaining behavioral change goals predicts volitional personality change. Fournal of Personality and Social Psychology, 117(4), 839-857. https://doi.org/10.1037/pspp0000221

Jackson, J. J., \& Beck, E. D. (2021). Personality development beyond the mean: Do life events shape personality variability, structure, and ipsative continuity. The fournals of Gerontology. Series B, Psychological Sciences and Social Sciences, 76(1), 20-30. https://doi.org/10.1093/geronb/gbaa093

James, W. (1892/1953). Psychology: A briefer course. Fawcett.

Krauss, S., Orth, U., \& Robins, R. W. (2020). Family environment and self-esteem development: A longitudinal study from age 10 to 16. Fournal of Personality and Social Psychology, 119(2), 457-478. https://doi.org/10.1037/pspp0000263

Krizan, Z., \& Herlache, A. D. (2018). The narcissism spectrum model: A synthetic view of narcissistic personality. Personality and Social Psychology Review, 22(1), 3-31. https://doi.org/10.1177/1088868316685018

Kwang, T., \& Swann, W. B. (2010). Do people embrace praise even when they feel unworthy? A review of critical tests of self-enhancement versus self-verification. Personality and Social Psychology Review, 14(3), 263-280. https://doi.org/10.1177/1088868310365876

Leary, M. R. (2004). What is the self? A plea for clarity. Self and Identity, 3(1), 1-3. https://doi.org/10.1080/13576500342000004

Lilgendahl, J. P., Helson, R., \& John, O. P. (2013). Does ego development increase during midlife? The effects of openness and accommodative processing of difficult life events. fournal of Personality, 81(4), 403-416. https://doi.org/10.1111/jopy.12009

Lysaker, P. H., \& Lysaker, J. T. (2010). Schizophrenia and alterations in self-experience: A comparison of six perspectives. Schizophrenia Bulletin, 36(2), 331-340. https://doi.org/10.1093/schbul/sbn077

Marcia, J. E., Waterman, A. S., Matteson, D. R., Archer, S. L., \& Orlofsky, J. L. (1993). Ego identity: An handbook for psychosocial research. Springer-Verlag.

McAdams, D. P. (2020). The strange case of Donald f. Trump: A psychological reckoning. Oxford University Press. 
McAdams, D. P. (2021). Narrative identity and the life story. In O. P. John \& R. W. Robins (Eds.), Handbook of personality: Theory and research (4th ed., pp. 122-141). Guilford Press.

McAdams, D. P., \& Guo, J. (2015). Narrating the generative life. Psychological Science, 26(4), 475-483. https://doi.org/10.1177/0956797614568318

McAdams, D. P., \& McLean, K. C. (2013). Narrative identity. Current Directions in Psychological Science, 22(3), 233-238. https://doi.org/10.1177/0963721413475622

McAdams, D. P., \& Pals, J. L. (2006). A new Big Five: Fundamental principles for an integrative science of personality. The American Psychologist, 61(3), 204-217. https://doi.org/10.1037/0003-066X.61.3.204

McCrae, R. R., \& Costa, P. T., Jr. (2008). The five-factor theory of personality. In O. P. John, R. W. Robins, \& L. A. Pervin (Eds.), Handbook of personality: Theory and research (3rd ed., pp. 159-180). Guilford Press.

McLean, K. C., \& Syed, M. (2015). Personal, master, and alternative narratives: An integrative framework for understanding identity development in context. Human Development, 58, 318-349. https://doi.org/10.1159/000445817

McLean, K. C., Syed, M., Pasupathi, M., Adler, J. M., Dunlop, W., Drustrup, D., Fivush, R., Graci, M., Lilgendahl, J., Lodi-Smith, J., McAdams, D. P., \& McCoy, T. (2020). The empirical structure of narrative identity: The initial Big Three. Journal of Personality and Social Psychology, 119(4), 920-944. https://doi.org/10.1037/pspp0000247

Mead, G. H. (1934). Mind, self, and society. University of Chicago Press.

Mischel, W., \& Shoda, Y. (1995). A cognitive-affective systems theory of personality: Reconceptualizing situations, dispositions, dynamics, and invariance in personality structure. Psychological Review, 102(2), 246-268. https://doi.org/10.1037/0033-295X.102.2.246

Oishi, S., Kushlev, K., \& Benet-Martinez, V. (2021). Culture and personality: Current directions. In O. P. John \& R. W. Robins (Eds.), Handbook of personality: Theory and research (4th ed., pp. 686-703). Guilford Press.

Orth, U., Erol, R. Y., \& Luciano, E. C. (2018). Development of self-esteem from age 4 to 94 years: A meta-analysis of longitudinal studies. Psychological Bulletin, 144(10), 1045-1080. https://doi.org/10.1037/bul0000161

Orth, U., \& Robins, R. W. (2019). Development of self-esteem across the lifespan. In D. P. McAdams, R. L. Shiner, \& J. L. Tackett (Eds.), Handbook of personality development (pp. 328-344). Guilford Press.

Orth, U., Robins, R. W., \& Widaman, K. F. (2012). Life-span development of self-esteem and its effects on important life outcomes. Journal of Personality and Social Psychology, 102(6), 1271-1288. https://doi.org/10.1037/a0025558

Ozer, D. J., \& Benet-Martinez, V. (2006). Personality and the prediction of consequential outcomes. In S. T. Fiske, A. E, Kazdin, \& D. L. Schacter (Eds.), Annual review of psychology (Vol. 57, pp. 401-421). Annual Reviews.

Reijula, S., \& Hertwig, R. (2020). Self-nudging and the citizen choice architect. Behavioural Public Policy, 1-31. https://doi.org/10.1017/bpp.2020.5 
Robins, R. W. (2021). Naturalizing the self. In O. P. John \& R. W. Robins (Eds.), Handbook of personality: Theory and research (4th ed., pp. 561-586). Guilford Press.

Schriber, R. A., \& Robins, R. W. (2012). Self-knowledge: An individual-differences perspective. In S. Vazire \& T. D. Wilson (Eds.), Handbook of self-knowledge (pp. 105-127). Guilford Press.

Schriber, R. A., Robins, R. W., \& Solomon, M. (2014). Personality and self-insight in individuals with autism spectrum disorders. fournal of Personality and Social Psychology, 106(1), 112-130. https://doi.org/10.1037/a0034950

Shahar, G. (2020). The Subjective-Agentic Personality Sector (SAPS): Introduction to the special issue on self, identity, and psychopathology. fournal of Personality, 88(1), 5-13.

https://doi.org/10.1111/jopy.12497

Shiner, R. L., Klimstra, T. A., Denissen, J. J. A., \& See, A. Y. (2021). The development of narrative identity and the emergence of personality disorders in adolescence. Current Opinion in Psychology, 37, 49-53. https://doi.org/10.1016/j.copsyc.2020.07.024

Tacikowski, P., Berger, C. C., \& Ehrsson, H. H. (2017). Dissociating the neural basis of conceptual self-awareness from perceptual awareness and unaware self-processing. Cerebral Cortex, 27(7), 3768-3781. https://doi.org/10.1093/cercor/bhx004

Tracy, J. L., Robins, R. W., \& Tangney, J. (2007). The self-conscious emotions: Theory and research. Guilford Press.

Trzesniewski, K. H., Donnellan, M. B., \& Robins, R. W. (2003). Stability of self-esteem across the lifespan. Fournal of Personality and Social Psychology, 84(1), 205-220. https://doi.org/10.1037/0022-3514.84.1.205

Tsai, J. L. (2007). Ideal affect: Cultural causes and behavioral consequences. Perspectives on Psychological Science, 2(3), 242-259. https://doi.org/10.1111/j.1745-6916.2007.00043.x

Vazire, S. (2010). Who knows what about a person? The self-other knowledge asymmetry (SOKA) model. Journal of Personality and Social Psychology, 98(2), 281-300. https://doi.org/10.1037/a0017908

Weiss, A. (2021). Personality in animals: What can we learn from a species-comparative approach? In O. P. John \& R. W. Robins (Eds.), Handbook of personality: Theory and research (4th ed., pp. 176-192). Guilford Press.

Wrzus, C., \& Roberts, B. W. (2017). Processes of personality development in adulthood: The TESSERA framework. Personality and Social Psychology Review, 21(3), 253-277. https://doi.org/10.1177/1088868316652279

\section{eapp}

Personality Science (PS) is an official journal of the European Association of Personality Psychology (EAPP).
(4) leibniz-psychology.org

PsychOpen GOLD is a publishing service by Leibniz Institute for Psychology (ZPID), Germany. 